УДК 378.14

\title{
ОПЫТ ПРОВЕДЕНИЯ ЭКЗАМЕНА ПО ИНОСТРАННОМУ ЯЗЫКУ В ВУЗЕ В УСЛОВИЯХ ДИСТАНЦИОННОГО ОБУЧЕНИЯ. ВЫЗОВЫ И ВОЗМОЖНОСТИ
}

\author{
Бяковская Надежда Геннадьевна \\ Старший преподаватель \\ Вербицкая Светлана Владимировна \\ Старший преподаватель \\ Сагайдак Наталья Алексеевна \\ Доцент \\ Государственный университет «Дубна»
}

Аннотация: В статье описывается специфика проведения экзамена по иностранному языку в вузе в условиях дистанционного обучения и предлагаются инструменты оптимизации процессов подготовки и проведения такого экзамена с точки зрения как содержания экзамена, так и его методической организации.

Ключевые слова: образование, дистанционное обучение, онлайн, экзамен, университет, вуз, иностранный язык, английский язык, Google, PowerPoint

\section{ORGANIZING AND CONDUCTING A FOREIGN LANGUAGE EXAM AT UNIVERSITY IN A DISTANCE LEARNING ENVIRONMENT. CHALLENGES AND OPPORTUNITIES}

\section{Byakovskaya Nadezhda Gennadievna Verbitskaya Svetlana Vladimirovna Sagaidak Natalia Alekseevna}

\footnotetext{
Abstract: The article describes the challenges of organizing and conducting a university exam in a foreign language in a distance learning environment and suggests ways to enhance the efficiency of these processes from the point of view of both content and form.

Key words: education, distance learning, online, exam, university, foreign languages, English, Google, PowerPoint.
} 
Для системы образования пандемия коронавируса стала глобальным вызовом: свыше 1.6 миллиарда учащихся и студентов образовательных учреждений в 161 стране мира были экстренно переведены на дистанционное обучение [1]. Ректор РАНХиГС при Президенте Российской Федерации Владимир Мау в интервью РБК сравнил ситуацию с прыжком на ходу из одного автомобиля в другой: настолько невыполнимой казалась эта задача [2]. Среди всего прочего вузы нашей страны должны были срочно решать, как организовать итоговую аттестацию в условиях новой реальности и предоставить возможность студентам продемонстрировать те компетенции, которыми они овладели за время обучения. Министерство образования предоставило вузам право выбора конкретных решений в проведении экзаменов. В каждом вузе прорабатывались различные форматы экзаменов в дистанционной форме для каждой преподаваемой дисциплины с учетом её специфики. Необходимо было также определить те цифровые технологии, которые бы помогли качественно провести аттестацию. Цель данной статьи поделиться собственным опытом проведения экзамена по английскому языку в вузе в условиях дистанционного обучения.

Нет необходимости напоминать, что иноязычная коммуникативная компетенция имеет многоаспектный характер и складывается из целого набора компонентов. Их состав варьируется в трактовках разных ученых, но в наиболее полном виде коммуникативная компетенция может быть описана как «языковая, речевая, социокультурная, включающая социолингвистическую, предметную, общекультурную и лингвострановедческую компетенции» [3].

Bce это определяет специфику преподавания иностранного языка, особенно студентам языковых ВУЗов или специальностей. Сложившимся традиционным подходом в таком профильно-ориентированном преподавании является многоаспектность, при которой различные виды коммуникативной компетенции формируются в условиях углубленного изучения грамматики, фонетики, практики устной и письменной речи и некоторых других аспектов.

Поскольку любое итоговое испытание должно отражать основные вопросы содержания дисциплины, задачу экзамена по основному иностранному языку можно сформулировать так: проверка сформированности всех основных коммуникативных навыков, необходимых для осуществления межъязыковой коммуникации по всем аспектам дисциплинь. Другими словами, на экзамене оцениваются такие навыки студентов, как понимание звучащей речи, владение сложными грамматическими конструкциями и лексическими единицами определенного тематического диапазона, умение порождать монологическую и диалогическую речь. Очевидно, что для решения этой комплексной задачи 
единственно возможным является формат устного экзамена, так как тестовый формат не позволяет проверить коммуникативные навыки.

При этом фокусом внимания на устном экзамене по иностранному языку должна быть проверка сформированности навыка порождения неподготовленной речи, что подразумевает способность решать коммуникативно-мыслительные задачи без затрат (или с минимальными затратами) времени на подготовку и использовать усвоенный языковой материал даже в незнакомых ситуациях общения [4, с. 186]. Неподготовленная речь может быть реализована на репродуктивно-продуктивном и продуктивном уровнях, которые различаются степенью самостоятельности высказывания и объемом собственного речевого творчества.

Однако как максимально эффективно реализовать устный формат экзамена в условиях дистанционного обучения? Ответ напрашивается сам собой: с помощью онлайн-технологий. Необходимость их использования неоспорима, и их польза несомненна. Тем не менее, с использованием средств дистанционного обучения при проведении экзамена связан целый ряд сложностей, которые, возможно, не заметны на первый взгляд, но от успешности преодоления которых во многом зависит качество самого экзамена.

Во-первых, это вероятность возникновения технических проблем, не зависящих от воли участников экзамена, таких, как отсутствие стабильного интернет-соединения или возможное отключение электроэнергии, которые могут сказаться на результате экзамена. Во-вторых, возможные личные финансовые затраты, связанные с необходимостью покупки новых устройств (компьютера, ноутбука, гарнитуры) для обеспечения более качественной связи. В-третьих, временны́е издержки. Подготовка к проведению экзамена в дистанционном формате требует несравнимо больше времени, чем подготовка к проведению экзамена в аудиторных условиях. В-четвертых, невозможность полностью проконтролировать соблюдение норм академической этики студентами и исключить случаи студенческого мошенничества. И, наконец, некоторые психологические неудобства, как для студентов, так и для преподавателей. Согласно опросам, проведенным на нашей кафедре, подавляющее большинство студентов и преподавателей предпочитают аудиторные занятия дистанционному обучению, даже несмотря на то, что большинство из них являются достаточно уверенными пользователями средств дистанционного обучения и не испытывают сколько-нибудь существенных технических проблем в процессе их использования.

Решение задачи успешного преодоления всех этих сложностей - это и вызов, и открывающиеся нам новые возможности. Проделав этот сложный путь и обогатившись собственным опытом проведения экзамена по иностранному 
языку в новых непростых условиях дистанционного обучения, мы хотели бы поделиться им в надежде, что он может кому-то пригодиться.

\section{Содержательные и организационные нововведения}

С учётом возникших новых обстоятельств, изложенных выше, нами был предложен и реализован новый формат экзамена по английскому языку.

Изменения коснулись, в первую очередь, содержания экзамена. Дистанционный формат устного экзамена и сокращение времени на подготовку ответа наложили определенные ограничения на использование творческих заданий подготовленного характера, например, таких, как подготовка и представление комментария по тексту или заданной теме. Для качественного выполнения подобных заданий студентам требуется, как правило, не менее 30 минут на подготовку и 5-10 минут на ответ. В условиях аудиторного проведения экзамена это не вызывало сложностей, поскольку процесс подготовки нескольких студентов происходил одновременно. А в условиях дистанта, при необходимости более тщательного отслеживания процесса подготовки ответа и, следовательно, строго последовательного (а не одновременного) участия студентов в экзамене, невозможно выделить такое количество времени на подготовку и ответ всего лишь одного вопроса билета. Поэтому виды заданий, входящих в структуру экзамена, надо было изменить, при этом, что немаловажно, возникшие ограничения не должны были сказаться на качестве предлагаемых новых экзаменационных заданий.

В результате в экзаменационный билет были включены три задания: монологическое высказывание репродуктивно-продуктивного характера, беседа с преподавателем по предложенной теме и монологическое высказывание продуктивного характера.

Задание 1 - монологическое высказывание репродуктивно-продуктивного характера, представляло собой вопрос по темам пройденного курса, требующий интерпретации изученного материала (время на подготовку - 5-7 минут, время на ответ - 2-3 минуты). Ответ должен был быть построен на основе информации, которая обсуждалась в рамках курса, однако студенту необходимо было проявить умение анализировать и синтезировать знакомую информацию, выразить свое отношение к фактам и событиям, дать им свою оценку, аргументировать собственную точку зрения, построить высказывание в соответствии со своим замыслом, продемонстрировав при этом владение тематической лексикой.

Задание 2 - спонтанная беседа с преподавателем по предложенной теме (время на подготовку - 1 минута, время на ответ - 5-7 минут). Студент получал проблемный вопрос по одной из тем курса. Ответ студента носил продуктивный характер: необходимо было выразить собственную точку зрения 
по поставленному вопросу, аргументировать ее, при ответе на дополнительные вопросы продемонстрировать умение вести дискуссию, выразить свое отношение к точке зрения собеседника, используя тематическую лексику.

Задание 3 - монологическое высказывание продуктивного характера, заключалось в создании новостной статьи по предложенному заголовку (время на подготовку - 3 минуты, время на ответ -2 минуты). Студент должен был продемонстрировать умение ориентироваться в англоязычной прессе, сопоставлять и обобщать информацию, использовать информацию газетных статей для аналитических целей, чтобы подготовить сообщение на актуальные проблемы социального, экономического и политического характера с максимальным использованием тематической лексики и широким спектром грамматических структур, характерных для средств массовой информации.

Таким образом, благодаря преимущественно неподготовленному, проблемному и личностно-значимому характеру предложенных заданий удалось минимизировать время, отведенное на подготовку ответа, сохранив при этом достаточное количество времени на ответ продуктивного характера, что позволило проверить сформированность всех основных коммуникативных навыков, необходимых для осуществления межъязыковой коммуникации.

Что касается сугубо организационной составляющей подготовки и проведения экзамена, она претерпела еще большие изменения, чем содержание экзамена. Эти изменения были обусловлены желанием сохранить качество экзамена, его объективность и беспристрастность. Во-первых, дистанционным форматом экзамена была продиктована необходимость придумать новую систему приглашения студентов в комнату видеоконференции экзамена и выбора экзаменационного билета, а также необходимость выработать правила поведения студентов и преподавателей в комнате видеоконференции экзамена, чтобы создать максимально комфортные условия для продуктивной работы. Во-вторых, возникла потребность более тщательного мониторинга процесса подготовки и ответа каждого студента с целью предотвращения нарушения норм академической этики (студенческого мошенничества), что подразумевало среди прочего решение таких задач, как присутствие в комнате видеоконференции только одного студента и, как следствие, минимизация времени на подготовку ответа студента. В-третьих, предстояло оптимизировать процесс взаимодействия членов экзаменационной комиссии и принятия коллегиальных решений.

Все введенные изменения, конечно же, были реализованы с применением современных информационно-коммуникационных технологий и средств дистанционного обучения. Рассмотрим эти нововведения поэтапно: на доэкзаменационном и экзаменационном этапах, - уделяя особое внимание 
инструментам и техникам, позволяющим оптимизировать экзаменационный процесс в условиях дистанта.

\section{Этап 1. До экзамена}

Основная цель доэкзаменационного этапа - обеспечить качественное и технически бесперебойное проведение экзамена. Это подразумевает решение таких задач, как определение порядка проведения экзамена, правил поведения в комнате видеоконференции, проверка технической готовности студентов и снятие психологической напряженности. Рассмотрим некоторые способы, способствующие решению данных задач.

1) График экзамена

Для того чтобы обеспечить последовательное подключение студентов к комнате видеоконференции экзамена в нужное время, был составлен график экзамена, размещенный в виде Google Документа в открытом доступе. Такая форма публикации графика удобна тем, что если в график придется вносить изменения, они будут сразу же видны любому пользователю этого документа. В таком случае можно быть уверенным в том, что студенты пользуются актуальной версией графика экзамена.

На каждого студента отводилось 30 минут, что включало как время подготовки ответа и сам ответ, так и время для дополнительных вопросов. Со студентами была достигнута договоренность о том, что каждый студент заходит в комнату видеоконференции за 5-10 минут до времени, указанного в графике сдачи экзамена, и дожидается завершения ответа предыдущего студента. Микрофон ожидающего студента при этом выключен, чтобы не мешать ответу другого студента, а камера включена, чтобы члены экзаменационной комиссии видели, что студент не испытывает технических сложностей и готов принимать участие в экзамене.

2) Памятка для студентов

Памятка для студентов представляет собой описание порядка проведения экзамена и правил поведения на экзамене. Памятка рассылается студентам по электронной почте за несколько дней до экзамена. Представляется важным включить в памятку следующую информацию:

- описание технических условий проведения экзамена (указание образовательной платформы, ссылка на экзамен или указание того, где находится эта ссылка, и т.п.);

- ссылку на график проведения экзамена;

- требования к технической подготовке студентов (наличие камеры, микрофона, наушников, стабильного интернета и запасного канала связи, желательно с отличным от основного способом доступа в интернет, а также 
требования к установке камеры - например, таким образом, чтобы лицо студента было видно анфас и полностью);

- что нужно иметь при себе на экзамене (документ, подтверждающий личность, - зачётную книжку или студенческий билет; бумагу для письма, несколько ручек, воду);

- правила поведения в комнате видеоконференции (условия использования камеры и микрофона, нормы академической этики);

- описание самой процедуры экзамена (ожидание своего ответа, идентификация личности, выбор билета, ответ на вопросы билета, участие в объявлении результатов);

- правила поведения при наступлении форс-мажорных обстоятельств во время подготовки или ответа студента (отключение электроэнергии, плохая связь, невозможность подсоединения к видеоконференции и другие технические неполадки, препятствующие участию в экзамене).

3) Чек-лист в виде Google Формы

Чек-лист представляет собой анкету, которую студенты заполняют за дватри дня до экзамена. Чек-лист преследует три важные цели:

- напомнить студентам о самых важных аспектах участия в экзамене,

- повысить уверенность студентов в своей готовности к экзамену,

- собрать информацию о готовности студентов к экзамену, которая может быть использована в ходе «технической» консультации, а также для отчетности.

К примеру, чек-лист может включать в себя следующие вопросы: «Какой запасной канал связи Вы предусмотрели? Выберите тип устройства» (стационарный компьютер / планшет / ноутбук / смартфон / другое); «Вам понятен формат Задания 2 (беседа с экзаменатором)?» (1-2-3-4-5); «Если Вам не понятен формат Задания 2, уточните, что именно непонятно».

При составлении чек-листа целесообразно придерживаться следующих принципов:

- не допускать анонимного участия в опросе (при анализе результатов удобнее понимать, кто именно из студентов дал тот или иной ответ);

- содержание вопросов должно быть очень конкретным и отражать содержание памятки, выданной студентам за несколько дней до экзамена, т.е. освещать такие важные аспекты участия в экзамене, как техническую готовность, внешний вид, состояние рабочего места в кадре, правила поведения студентов;

- в чек-лист также рекомендуется включить вопросы о том, насколько (например, по шкале от 1 до 5) студенту понятен формат и критерии 
оценивания каждого из вопросов экзамена по отдельности, а также вопрос о способах подготовки студентов к экзамену;

- чек-лист должен содержать не только вопросы, но и следующие за вопросами короткие комментарии или пояснения, указывающие на правильный ответ и напоминающие студенту о порядке проведения экзамена и правилах поведения на экзамене (рис. 1);

- рекомендуется использовать такой стиль вопросов и комментариев, который бы создавал ощущение, что чек-лист - это не проверка студентов, а инструмент помощи и самоорганизации.

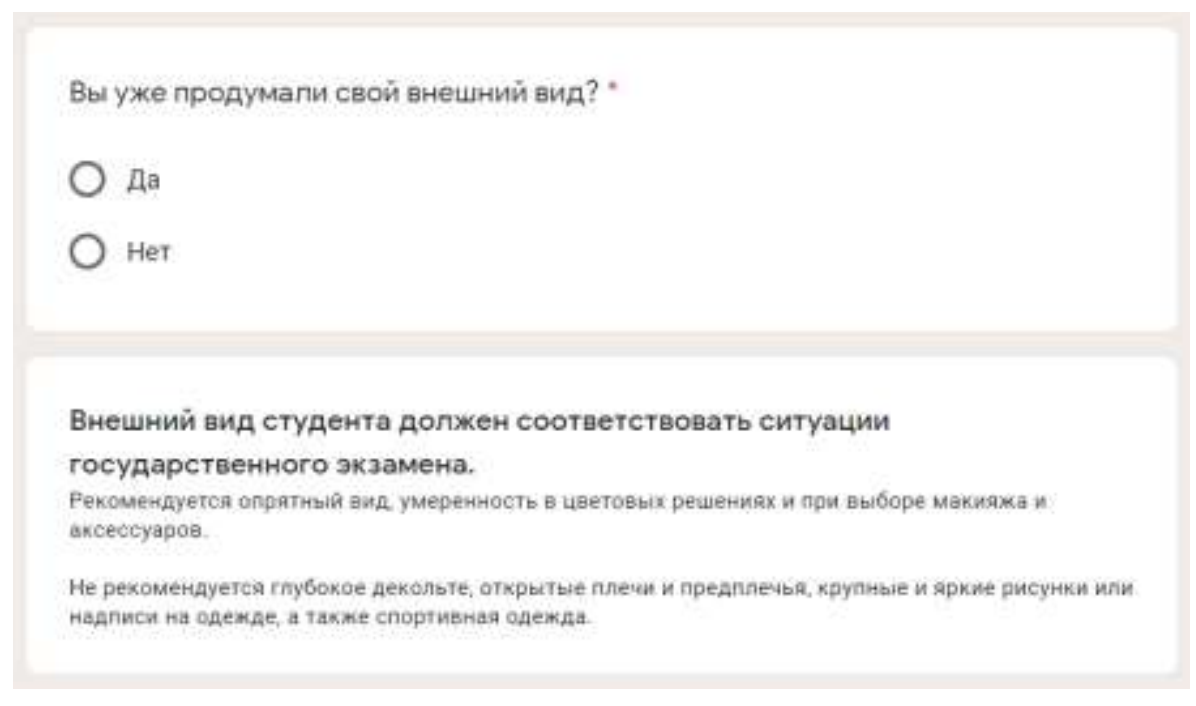

\section{Рис. 1 Пример вопроса и комментария в чек-листе}

К преимуществам использования Google Формы относятся простота создания чек-листа и наглядная аналитика. Ответы студентов можно просматривать в виде сводки с диаграммами, отражающими статистку ответов на каждый вопрос, в виде списка ответов каждого студента на все вопросы анкеты или в виде списка ответов всех студентов на каждый вопрос анкеты.

В ходе предэкзаменационного анкетирования наших студентов было выявлено, что у трех студентов не было доступа к зачетной книжке, которая первоначально была предусмотрена как способ идентификации личности студента, что не все студенты продумали свой внешний вид, и что у одного студента не было установлено приложение WhatsApp, которое предполагалось использовать как канал оперативной связи между преподавателями и студентами на экзамене. Все эти недочеты, благодаря своевременному выявлению, были устранены до экзамена.

4) «Техническая» консультация 
На «технической» консультации, которая проводится накануне экзамена, необходимо проверить техническую готовность студентов к экзамену (камеру, звук, микрофон), а также отрепетировать со студентами ключевые моменты процедуры экзамена (вход в комнату видеоконференции, идентификация личности, выбор билета, работу запасного канала связи со студентами и т.п.). Важно, чтобы «техническая» консультация проходила в условиях, максимально приближенных к экзаменационным: это поможет студентам чувствовать себя психологически комфортнее во время экзамена. Необходимо пользоваться именно теми средствами дистанционного обучения, которые будут использоваться и во время экзамена.

\section{Этап 2. В день экзамена}

Основной целью экзаменационного этапа является добиться максимально качественного проведения экзамена. Это включает в себя решение таких задач, как тщательный мониторинг соблюдения норм академической этики, обеспечение беспристрастности и объективности экзаменационного процесса, а также обеспечение оперативного взаимодействия членов экзаменационной комиссии между собой и взаимодействия между студентами и экзаменационной комиссией. Данные задачи могут быть решены следующими способами.

\section{1) Видеозапись экзамена.}

Поскольку видеозапись экзамена может быть использована как дополнительное средство принятия решений (при выставлении оценки или апелляции), необходимо следить за тем, чтобы камера и микрофон студента были включены постоянно во время подготовки и ответа.

2) Идентификация личности студента.

Это является обязательным требованием для участия студента в экзамене. Как правило, используется два вида идентификации: цифровая идентификация (например, вход в комнату видеоконференции с помощью индивидуального логина и пароля), а также демонстрация на камеру удостоверения личности (студенческого билета или зачётной книжки).

3) Экзаменационные билеты в формате презентации PowerPoint.

Для того чтобы у студентов не возникало сомнений в объективности процедуры выбора билета, её следует максимально приблизить к процедуре выбора билета в аудиторных условиях, когда каждому билету соответствует заранее определенный набор вопросов и студент выбирает билет самостоятельно. Эти задачи успешно решаются путем составления билетов в виде презентации PowerPoint, которую технический секретарь демонстрирует на экране во время экзамена. 
На первом слайде презентации приводится список всех билетов (Билет 1, Билет 2 и т.д.), каждый из которых оформляется в виде гиперссылки на другой (каждый раз новый) слайд. При нажатии на выбранный студентом билет презентация переходит на слайд, соответствующий выбранному билету, где отображаются все вопросы, входящие в состав билета. При необходимости в настройках презентации можно задать показ каждого следующего вопроса в составе билета по щелчку мыши, чтобы студент не видел все вопросы билета сразу. После того, как студент ответил на все вопросы билета, использованный билет «вычеркивается» с первого слайда путем применения зачеркнутого шрифта. Не стоит удалять название билета со слайда: это приведет к нарушению работы презентации (рис. 2).

Выберите билет
Билет No7
$\begin{aligned} & \text { 1. Speculate on the correlation between hard work and } \\ & \text { opportunities that open before you. Is hard work a key to } \\ & \text { success? }\end{aligned}$
$\begin{aligned} & \text { 2. Discuss the following question with the examiner: } \\ & \text { "Leaders of the past are remembered thanks to their } \\ & \text { achievements, while modern leaders are famous for } \\ & \text { their failures. Do you agree?" }\end{aligned}$
$\begin{aligned} & \text { 3. Read the headline of the article and make a presentation } \\ & \text { based on the events in the world under the given } \\ & \text { headline: "Cemeteries braced for surge in deaths as } \\ & \text { Mexico readies to reopen". }\end{aligned}$

\section{Рис. 2 Пример оформления экзаменационных билетов в виде презентации PowerPoint}

4) Группы в WhatsApp (или другие средства обмена мгновенными сообщениями) как каналы оперативной связи:

a) для взаимодействия между экзаменационной комиссией и студентами. Такая группа может использоваться, например, когда необходимо оповестить студентов о существенных сдвигах в графике экзамена или чтобы студенты могли сообщить о возникших у них технических проблемах. Если экзамен проходит в течение нескольких дней, рекомендуется создать для каждого экзаменационного дня отдельную группу;

b) для оперативной связи членов комиссии между собой во время приема экзамена с целью обсуждения качества ответов студентов, оперативного принятия совместных решений и т.д.

5) Онлайн-ведомость в виде Google Таблицы.

Для упрощения принятия коллегиальных решений относительно оценок за ответы на экзамене удобно использовать онлайн-ведомость в виде Google 
Таблицы, которая открыта для совместного редактирования членов экзаменационной комиссии (рис. 3). Преимущество использования этого инструмента состоит в том, что таблица заполняется членами комиссии непосредственно в ходе экзамена, и средний балл за ответ высчитывается автоматически на основании оценок, выставленных каждым членом комиссии. Это особенно актуально при большом количестве вопросов в билете и / или большом количестве членов комиссии.

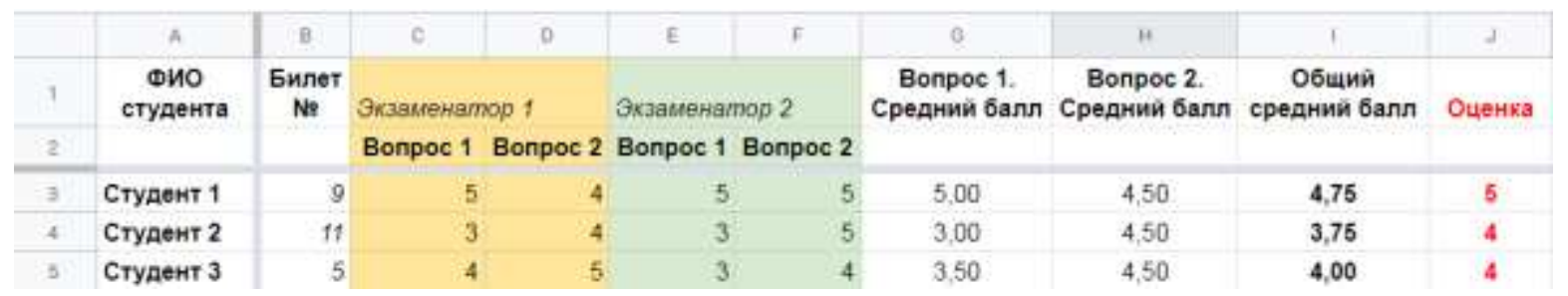

\section{Рис. 3 Пример оформления совместной онлайн-ведомости в Google Таблице}

Каждый экзаменатор имеет в этой ведомости свое поле для внесения оценок за каждый вопрос билета. Для удобства поле каждого экзаменатора можно выделить своим цветом и защитить диапазон, чтобы экзаменаторы по ошибке не заполнили чужое поле. Для более точного оценивания таблицу можно дополнить критериями оценивания для каждого вопроса билета и вносить оценки за каждый критерий. Средний балл удобно округлять до сотых, a финальную (итоговую) оценку выставлять вручную на основании автоматически посчитанного общего среднего балла. Использование подобной таблицы сильно сокращает время на обсуждение оценок по завершении экзамена.

Таким образом, в ходе подготовки и проведения экзамена по английскому языку в условиях дистанционного обучения нами был использован достаточно широкий набор средств, позволивших оптимизировать эти процессы и решить поставленные задачи на предэкзаменационном и экзаменационном этапах. Некоторые из этих средств, такие как памятка для студентов, чек-лист и онлайн-ведомость, могут быть успешно использованы и при аудиторной форме проведения экзамена в целях лучшей его организации. Другие же «заточены» именно под онлайн-формат и являлись скорее вынужденными мерами, чем результатом свободного методического творчества преподавателей, что, однако, не уменьшает их ценности. В целом, благодаря этим нововведениям, мы получили положительный опыт проведения экзамена по иностранному языку в условиях дистанционного обучения. 
Конечно, хочется надеяться, что опыт проведения экзаменов в таком формате не превратится в норму, ведь очевидно, что преодоление трудностей в экстремальных условиях не имеет ничего общего с продуманным и планомерным внедрением оправданных форм онлайн-обучения. Однако положительным в этом опыте, помимо решения сиюминутной задачи проведения экзамена в сложившихся обстоятельствах, видится еще и то, что он помог выявить и протестировать эффективные цифровые инструменты и технологии, которые, безусловно, можно и нужно использовать в работе офлайн. Именно такое обоснованное и разумное сочетание традиционных и новейших технологий должно привести к повышению качества образования.

\section{Список литературы}

1. Фрумин И., Реморенко И. Полтора миллиарда пропущенных уроков // Ведомости. - 2020. - 4 апреля. URL: https://www.vedomosti.ru/ society/articles/2020/04/04/827151-poltora (дата обращения 15.08.2020).

2. Мау В. Экзамен на пандемию: как вузы встречают новый вызов // РБК. - 2020. - 13 мая. URL: https://www.rbc.ru/opinions/society/13/05/ 2020/5ebaa24e9a794770bafc586e (дата обращения 15.08.2020).

3. Сафонова В. В. Коммуникативная компетенция: современные подходы к многоуровневому описанию в методических целях. - М.: Еврошкола, 2004. - 236 с.

4. Солонцова Л.П. Методика обучения иностранным языкам: в 3 частях: учебник для вузов (бакалавриат). - М.: Издательство ВЛАДОС, 2018. - Часть 1: Общие вопросы. Базовый курс. -272 с. 